BNL - 67922

Informal Report

\title{
Design Studies For The LCLS 120 Hz RF Gun
}

\author{
X.J. Wang, M. Babzien, I. Ben-Zvi, X.Y. Chang, S. Pjerov and M. Woodle \\ National Synchrotron Light Source \\ Brookhaven National Laboratory \\ Upton, New York 11973
}

December 2000

National Synchrotron Light Source

\author{
Brookhaven National Laboratory \\ Operated by \\ Brookhaven Science Associates \\ Upton, NY 11973
}

Under Contract with the United States Department of Energy

Contract Number DE-AC02-98CH10886 


\section{DISCLAIMER}

This report was prepared as an account of work sponsored by an agency of the United States Government. Neither the United States Government nor any agency thereof, nor any of their employees, nor any of their contractors, subcontractors or their employees, makes any warranty, express or implied, or assumes any legal liability or responsibility for the accuracy, completeness, or any third party's use or the results of such use of any information, apparatus, product, or process disclosed, or represents that its use would not infringe privately owned rights. Reference herein to any specific commercial product, process, or service by trade name, trademark, manufacturer, or otherwise, does not necessary constitute or imply its endorsement, recommendation, or favoring by the United States Government or any agency thereof or its contractors or subcontractors. The views and opinions of authors expresses herein do not necessarily state to reflect those of the United States Government or any agency thereof. 


\title{
Design Studies For The LCLS $120 \mathrm{~Hz}$ RF Gun Injector
}

\author{
X.J. Wang, M. Babzien, I. Ben-Zvi, X.Y. Chang, S. Pjerov, and M. Woodle \\ National Synchrotron Light Source \\ Brookhaven National Laboratory \\ Upton, NY 11973
}

(December 11,2000)

\begin{abstract}
A preliminary design studies were carried out at Brookhaven National Laboratory for a photocathode RF gun injection system for LCLS $120 \mathrm{~Hz}$ operation. The starting point for the design is $50 \mathrm{~Hz}$ BNL Gun IV developed by a BNL/KEK/SHI collaboration. The basic parameters of the $120 \mathrm{~Hz}$ gun is discussed in this report. The complete photocathode RF gun injection system is described for a $120 \mathrm{~Hz}$ operation. The injector system includes photocathode RF gun, emittance compensation solenoid magnet, laser system and laser beam delivery syst em, and electron beam diagnostics. The basic design parameters, mechanical modification and the performance will be presented in this report.
\end{abstract}

\section{Introduction}

The X-ray SASE free electron laser (FEL) project - LCLS now under development by a SLAC/ANL/BNL/LANL/LLNL/UCLA collaboration requires high -brightness photocathode RF gun capable of operating at $120 \mathrm{~Hz}$. BNL RF gun IV developed by a BNL/KEK/SHI collaboration now operating at APS LEUTL FEL, BNL SDL and Tokyo University was designed to operate at $100 \mathrm{~Hz}$, and has demonstrated capability of operating at $50 \mathrm{~Hz}$ with $4 \mu$ s RF pulse. The BNL Gun IV (Fig.1) was based on the experience of the BNL Gun III by a BNL/SLAC/UCLA collaboration. Major modifications Gun IV relative to Gun III are:

1. Water channels was added to improve the operating stability and for a 50 to $100 \mathrm{~Hz}$ operation.

2. Improve the Helical flex seal joint to avoid possible RF break down problem. This was realized by reduce the helical flex seal exposure to the RF field.

3. Instead of just a photocathode RF gun, we have developed an integral design of photocathode RF gun injection system, which consists of RF gun, solenoid magnet, laser and electron beam diagnostics stations. All basic parameters of the photocathode RF gun, such as the field on the cathode, charge, laser performance and laser relative to RF gun phase, can be determined within the injection system [1].

4. A better support structure was designed for easy installation and alignment of RF gun relative to the emittance compensation solenoid magnet.

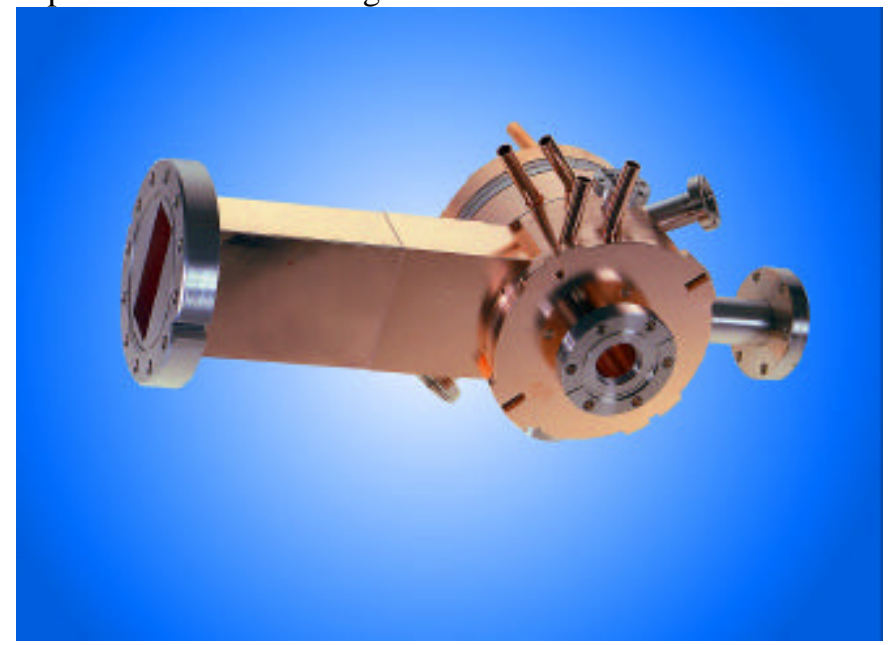

Fig.1: BNL photocathode RF gun IV. 
The basic parameters of the $120 \mathrm{~Hz}$ Photocathode RF gun injection system will be discussed first. We then present the modification required to operate the photocathode RF gun at $120 \mathrm{~Hz}$. We will also present the simulation carried out for the performance of the photocathode RF gun injection system. A brief discussion the laser system and its beam optics will be included.

\section{Photocathode RF Gun Parameters}

Base on the almost ten years experience of operating photocathode RF gun at the Brookhaven Accelerator Test Facility, we will present a complete set of parameters for the $120 \mathrm{~Hz}$ photocathode $\mathrm{RF}$ gun injection system.

I. Photocathode RF gun: The photocathode RF gun is designed for operating at the $120 \mathrm{~Hz}$, table I list the basic parameters for the RF gun. Two parameters have been not considered in previous design are vacuum and operating temperature. The operating temperature was lowered from $45 \mathrm{C}$ traditionally for the linac to $30 \mathrm{C}$, which reduces the resistivity by about $10 \%$. This is important for $120 \mathrm{~Hz} \mathrm{RF}$ gun development. Another important parameter is the vacuum inside the RF gun. Based on the experience we had at the ATF, vacuum is important metal cathode quantum efficiency and its life -time. With better vacuum, $0.5 \%$ quantum efficiency $(\mathrm{QE})$ of $\mathrm{Mg}$ cathode was measured with life time more than 30 days. Another advantage of good vacuum is that, QE can be restored using vacuum based laser cleaning technique [2].

Table 1: Photocathode RF Gun Specification.

\begin{tabular}{|l|l|}
\hline RF gun rep. Rate $(\mathrm{Hz})$ & 120 \\
\hline Field on the cathode $(\mathrm{Mv} / \mathrm{m})$ & $100-140$ \\
\hline Cathode material & $\mathrm{Cu}$ or $\mathrm{Mg}$ \\
\hline Vacuum inside the gun & $<3 \times 10^{-10}$ with RF on \\
\hline Operating Temperature $\left({ }^{\circ} \mathrm{C}\right)$ & 30 \\
\hline
\end{tabular}

II. Photocathode RF Gun Laser System: There are many studies which specified the performance requirements for the photocathode RF gun injection system. We felt different way of specify the laser system performance is required based on the operation experience we had at the ATF. One particular example is the timing jitter required for the laser system. Both our experiment and recent simulation shows much more strict requirements for a reliable performance. Most LCLS design requires $0.5 \mathrm{ps}$ (rms) timing jitter, which corresponding to about 2 ps (p-p) timing jitter. The new specification should be 0.1 ps (rms), and 0.5 ps (p-p), which we have demonstrated at the ATF most time. Another depart on specify the laser system is that, we think it is important to specify both rms and peak to peak value. Table II listed the laser parameter required for the $120 \mathrm{~Hz} \mathrm{RF}$ gun.

Table 2: Photocathode RF Gun laser system specification.

\begin{tabular}{|l|l|l|}
\hline & & \\
\hline Rep. Rate (Hz) & 120 & \\
\hline Laser energy on cathode (UV,uJ) & $30(\mathrm{Mg})$ & $200(\mathrm{Cu})$ \\
\hline Laser pulse length (ps, FWHM) & 5 to 20 & \\
\hline Laser spot (radius, mm) & $0.5-1.5$ & \\
\hline Laser energy stability (\%) & $1.5(\mathrm{rms})$ & $6(\mathrm{p}-\mathrm{p})$ \\
\hline Timing jitter (ps) & 0.1 & $0.5(\mathrm{p}-\mathrm{p})$ \\
\hline Point stability (\%) & 0.25 & 1 \\
\hline
\end{tabular}

\section{Mechanical Design of $120 \mathrm{~Hz}$ RF Gun}

A detail thermal analysis was performed for the BNL Gun IV (figure 2). For a $1 \mathrm{~kW}$ average input power, the temperature distribution of the RF gun is plotted in Fig.3. The maximum temperature gradient is about $5{ }^{\circ} \mathrm{C}$. The thermal mapping also has shown that, hot spots are the iris between two cells and the center 
portion of the cathode. Several preliminary modifications on the gun IV were made to improve the cooling capability. A water channel on the RF gun power input wave guide was added(Fig.4). To reduce the hot spot near the iris, the diameter of the water channel near the iris was increased, and it was pushed further close to the iris (Fig.5, and 6). We are also investigating the possibility of increase more cooling for the cathode surface. More detailed thermal mapping of the $120 \mathrm{~Hz}$ RF gun will be performed in next couple months if funding available.



Fig.3: Thermal mapping of BN L Gun IV for $1 \mathrm{KW} \mathrm{CW} \mathrm{power.}$

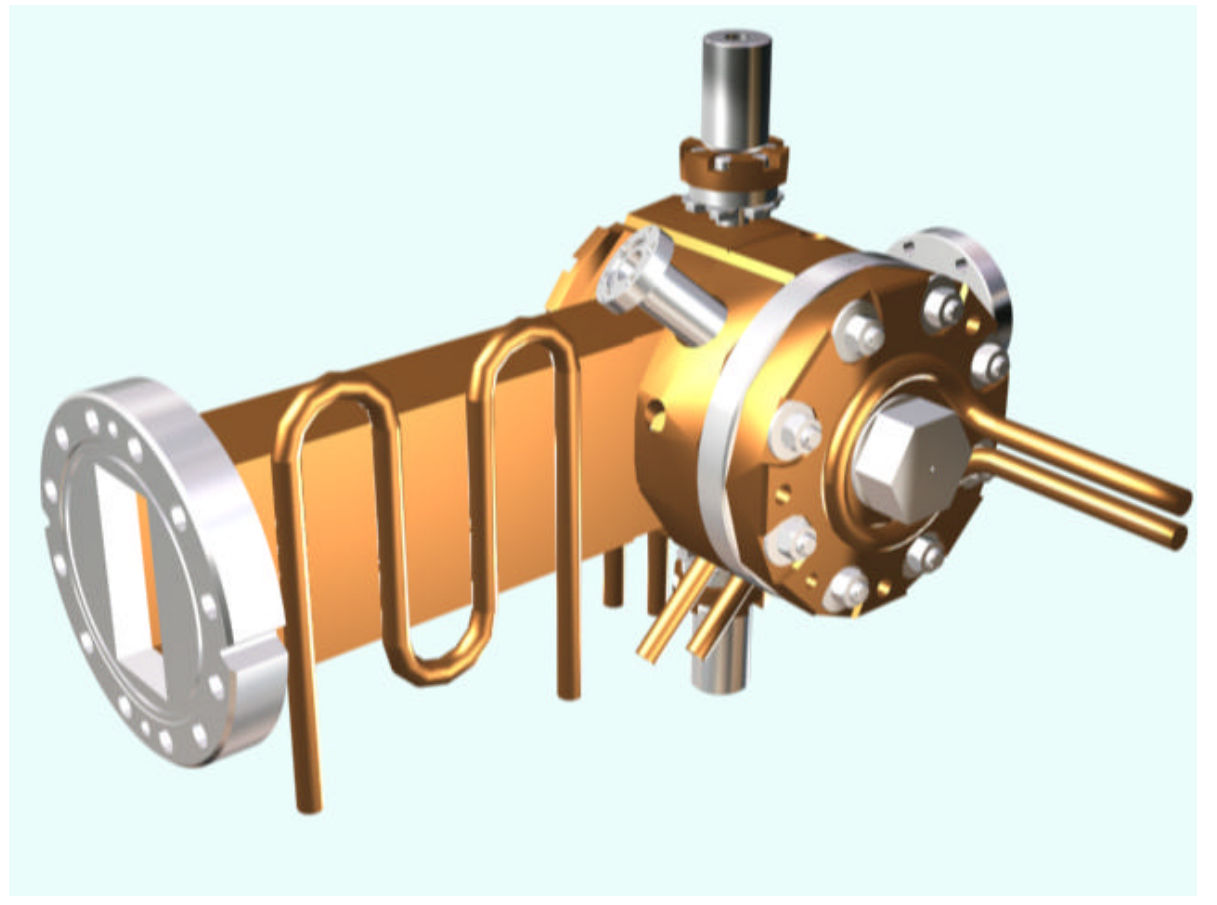

Fig.4: The schematic of $120 \mathrm{~Hz}$ RF Gun 


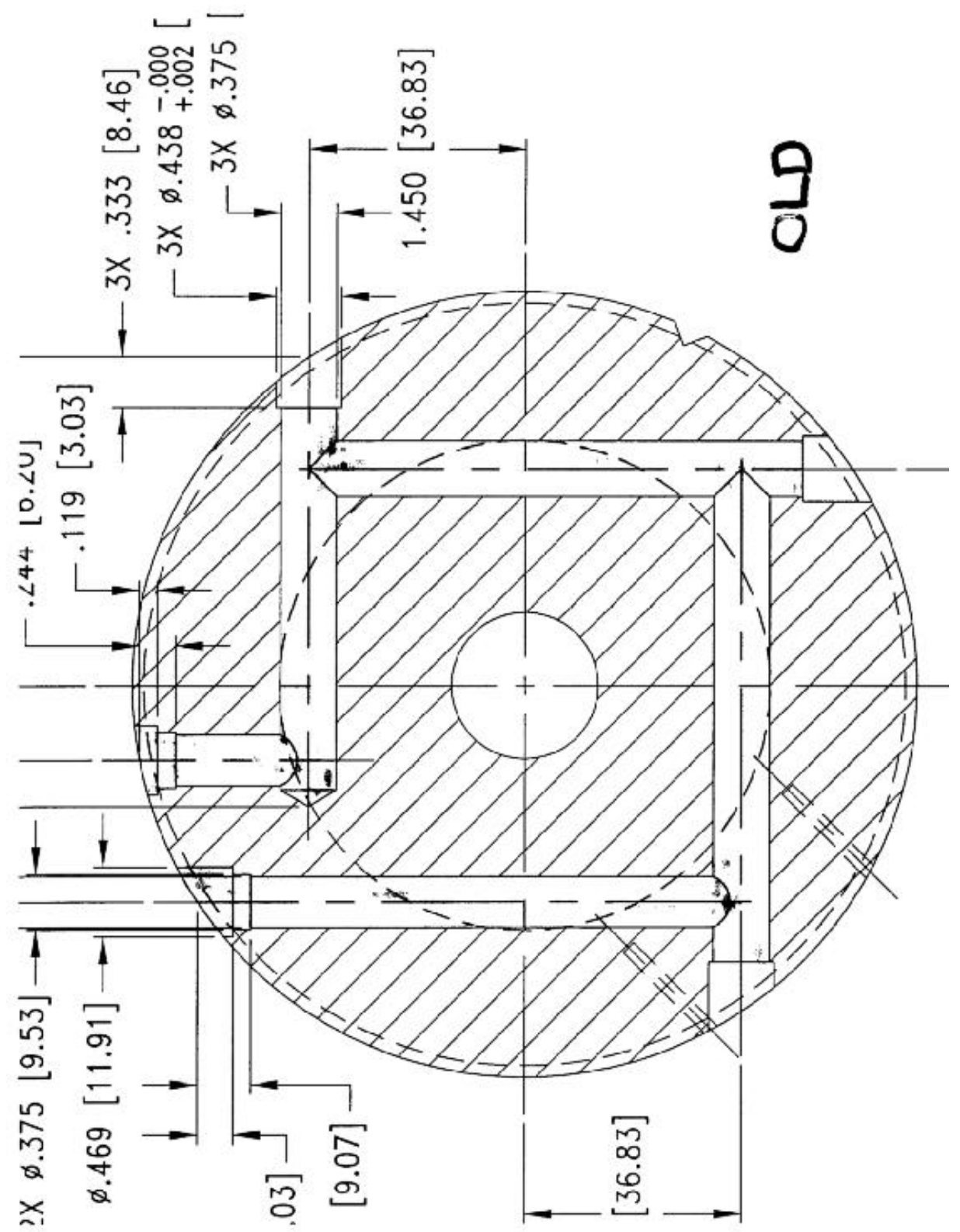

Fig.5: Water channel for BNL gun IV. 


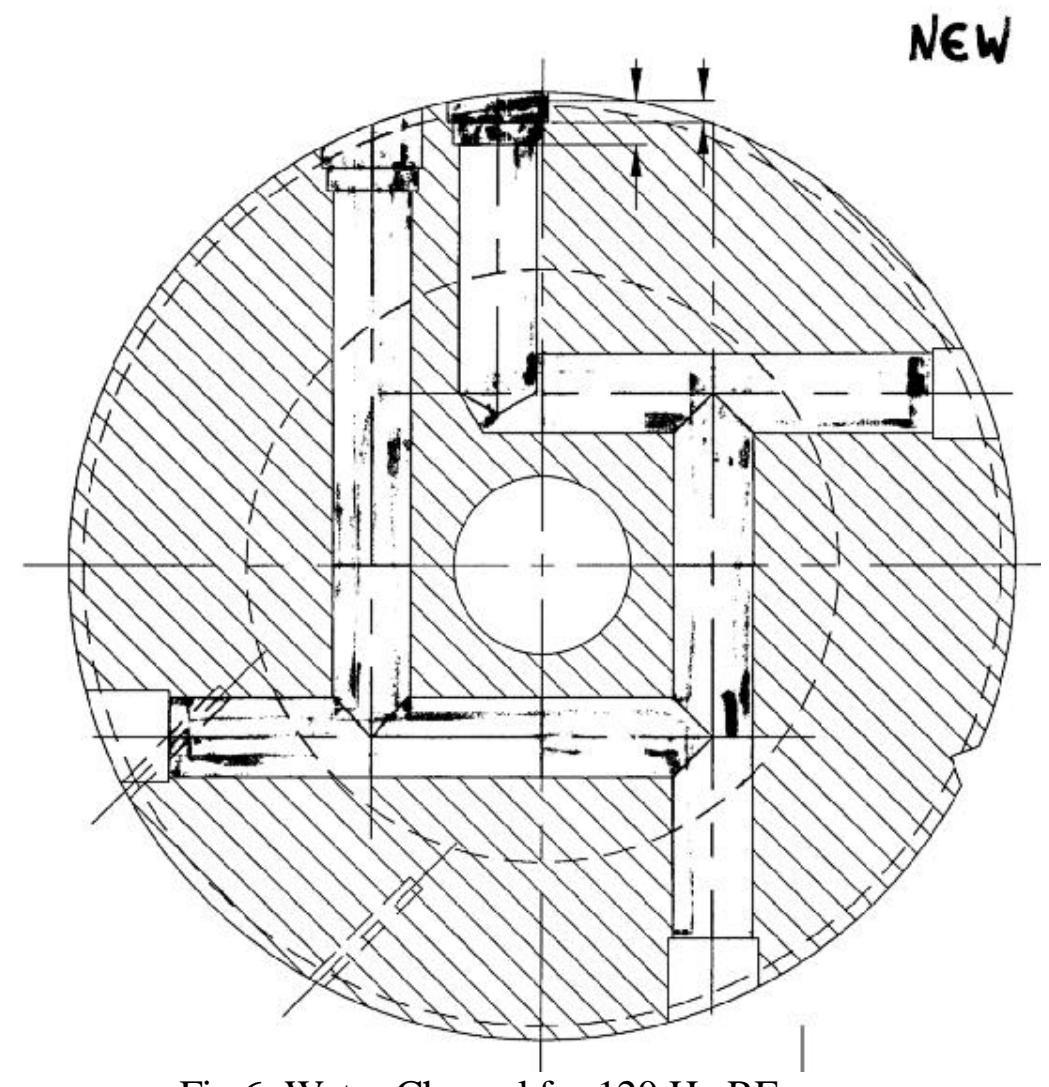

Fig.6: Water Channel for $120 \mathrm{~Hz}$ RF gun .

\section{Simulation of $120 \mathrm{~Hz}$ Photocathode RF gun Injection System}

A systematic study of the performance of the photocathode RF gun for $120 \mathrm{~Hz}$ operation was carried out using computer program PARMELA. Official version of the PARMELA program was used for the study. In order to better understanding, we added some minor capabilities of the program for both pre-processing and post-processing the data. For pre-processing, we can generate any electron beam distribution, which is important for studying the Schottky effect on the electron beam distribution. For post -processing, we can calculate electron beam parameters of any faction of the electron beam, such as slice and $90 \%$ of best beam


Fig.7: Emittance and bunch length as function of the RF gun phase for $10 \mathrm{ps}$ (FWHM) Gaussian laser pulse. Emittance (cm-mrad) is for $1 \mathrm{nC}$ charge.

The first issue we investigated is to solve the difference between the previous simulations $[3,4]$ and experiment results. One of the major differences is the RF gun phase dependency of the transverse 
emittance. Both Kim's theory and earlier simulation predicted the RF gun phase for minimum transverse emittance lies between 50 and 70 degree from the zero crossing. The best emittance measured at the ATF is about 30 degree [2]. Out latest simulation has the similar result (Fig.7). Lower RF gun operating $p$ hase has immediately several important implications for $120 \mathrm{~Hz}$ RF gun operation. One is the timing jitter specification, other is the longitudinal laser profile for the best emittance. Due to the Schottky effect, timing jitter now will directly introduce e lectron beam charge fluctuation, which also cause emittance fluctuation. Another effect is that, for longitudinal uniform laser profile (beer can model), The Schottky effect will introduce 30 to $50 \%$ charge density variation from heat to tail of the elect ron beam, which could lead to $20 \%$ emittance growth comparing to uniform electron longitudinal profile.

We also investigated various options shaping the electron beam longitudinal profile, specially using both electron beam and laser beam truncation. La ser beam truncation can be realized by saturable absorber, while electron beam truncation can be realized by slit at the dispersion region. We found that, the emittance achieved using truncation is about $20 \%$ larger than uniform longitudinal distribution $\mathrm{b}$ eam.

\section{Laser and Front-end Beam Optics}

Based on the latest simulation and ATF operation experience, we have been working with Sumitomo Heavy Industries (SHI) to develop a $120 \mathrm{~Hz}$ laser system to drive the photocathode RF gun. SHI now has a all solid st ate Nd: YLF laser operating at the $100 \mathrm{~Hz}$ satisfy the requirement set out in the earlier section [5]. The SHI PULRISR-100 is capable of produce $2 \mathrm{~mJ} @ 1047 \mathrm{~nm}$, and $0.2 \mathrm{~mJ}$ at $262 \mathrm{~nm}$, the 8 hour energy stability is $0.25 \%$ (rms), and $1 \%$ peak to peak. SHI int end to raise the repetition rate to $120 \mathrm{~Hz}$ in next year.

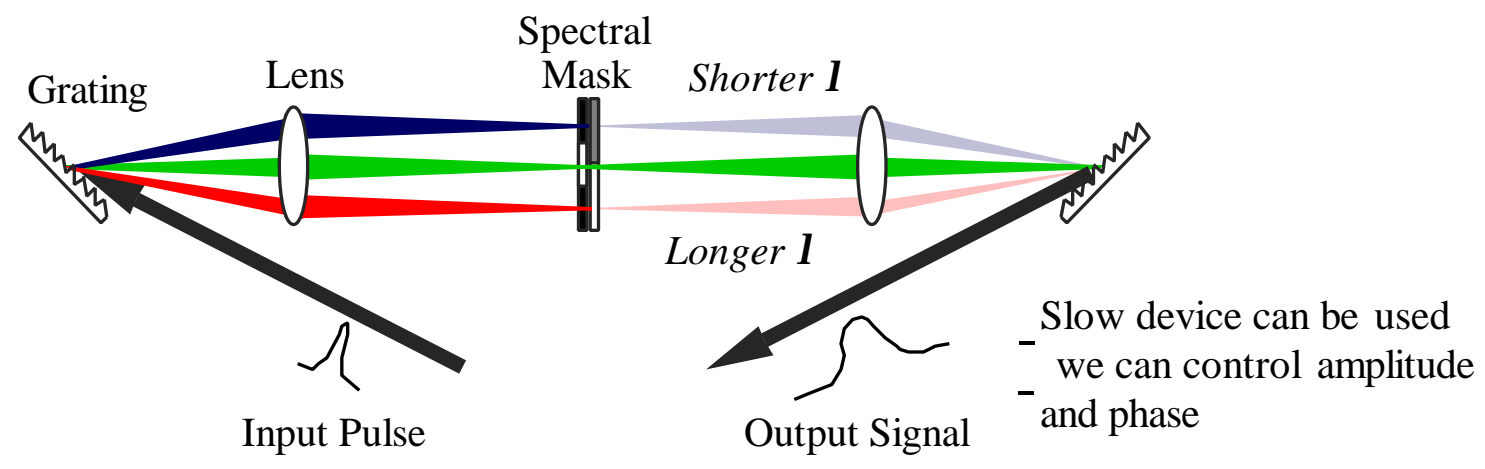

Fig.8: Longitudinal laser pulse shaping using spectral mask.

Oblique laser incident on the cathode will be the choice over the normal incident, the main reason for such laser optics is the laser beam diagnostics [6]. We plan to develop a complete laser and its beam delivery system with following capabilities:

1. longitudinal beam profile shaping based on either solid state saturable absorber, or laser phase mask (Fig.8).

2. Transverse beam profile shaping and control: Gaussian mirror will be investigated for transverse beam profile shaping. Another possibility of transverse beam profile shaping is based on the adaptive optics, which could be implemented with oblique incident optics.

3. On-line laser monitoring system: with oblique laser incident, we will develop laser optics delivery system which can measure the laser profile, energy and timing jitter.

\section{REFERENCE}

1. X.J. Wang. M. Babzien, I. Ben-Zvi, R. Malone, J. Sheehan, J. Skaritka, T. Sri nivasan-Rao, M. Woodle, V. Yakimenko and L.H. Yu, CHALLENGES OF OPERATING A PHOTOCATHODE RF GUN INJECTOR, Proceeding of XIX International Linac Conference, August 22 - 28, 1998, Chicago, Illinoi. 
2. X.J. Wang, M. Babzien, I. Ben-Zvi, R. Malone and V. Yakim enko, FEL Technologies and SASE Gain Enhancement Observation at the BNL ATF, Proceeding of EPAC 2000, BNL - 67635 (2000).

3. J. Gallardo and H. Kirk, An injection scheme for Brookhaven ATF ulilizing space -charge emittance growth compensation, Proceeding of PAC'93, 3615 (1993).

4. E. Colby et al, Design and Construction of High Brightness RF Photoinjectors for TESLA, Proceeding of PAC'95, 967 (1995).

5. A. Endo, SHI, private communication.

6. X.J. Wang, "Single -Pass High-Gain Free Electron Laser Beam Diagnostics" Proc eeding of the 9th Beam Instrumentation work shop, BNL - 67638 (2000). 